\title{
Is it useful to use several "omics" for obtaining valuable results?
}

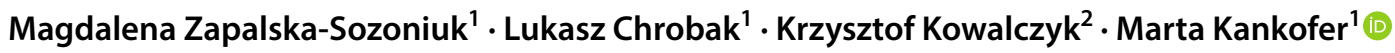

Received: 17 August 2018 / Accepted: 2 April 2019 / Published online: 15 April 2019

(c) The Author(s) 2019

\begin{abstract}
The integration of cell communication and the transfer of signals from stimuli via transcription to translation and further to activation of new protein is crucial for appropriate metabolism and function of living organisms. The overall elucidation and the examination of these complex processes require multistep laboratory approaches in order to obtain results which will not only detect particular stage but also indicate the mechanisms lying upon this process. Such results will be reliable because they will cover multidirectional methods and approaches. The analysis of currently available results already provided with the conclusion that often single omics approach does not correspond with other expected information and may bring misinterpretations. That is why the integration of several "omics" is useful for searching entire explanations and answers as well as appropriate interpretation of obtained complex results. The hypothesis was stated that "from transcriptomics can not be concluded to proteomics". This review focuses on the reasons for the integration of transcriptomic, proteomic and other-omics analysis. Moreover it also describes the examples of clinical meanings and mentions some methods used in these approaches.
\end{abstract}

Keywords Proteomics $\cdot$ Transcriptomics $\cdot$ Omics

\section{Background}

Appropriate system for transfer of information and its integration is crucial for the stimulation and regulation of physiological answer of the organism. It assures good relationship between macromolecules and flow of information necessary for good metabolism and functioning.

In addition differences among organisms make the elucidation of these relationships even more difficult because

Marta Kankofer

marta.kankofer@up.lublin.pl

Magdalena Zapalska-Sozoniuk

magdalena.zapalska@up.lublin.pl

Lukasz Chrobak

luzik2@op.pl

Krzysztof Kowalczyk

krzysztof.kowalczyk@up.lublin.pl

1 Departament of Biochemistry, Faculty of Veterinary Medicine, University of Life Science in Lublin, Akademicka Street 12, 20-033 Lublin, Poland

2 Institute of Plant Genetics, Breeding and Biotechnology, Faculty of Agrobioengineering, University of Life Sciences in Lublin, Akademicka Street 15, 20-950 Lublin, Poland the relation gene-protein is nowadays neither simple nor obvious.

General aspects of the flow of information from DNA to proteins are well known [1] and it can be concluded that all factors acting at the mRNA level will be reflected in the cell proteome. But even if the information from DNA is transcribed to mRNA properly still the synthesis of proteins can be altered and new molecule may not be biologically active. Moreover, selected metabolites might not be synthesized. The main problem to define is the regulation of flow of information and the metabolism of newly synthesized protein within the cell. Thanks to the development of new laboratory methods the regulation of every step in this scenario can be partly evaluated and described.

These new methods allow for the analysis not only on cell but also deeper on molecular level and the discovery of events which were not considered before such as DNA microarrays, miRNA or the identification of proteome. However, these methods are not sufficient enough to define the interactions of proteins for fully sequenced genome. Computer techniques can only predict these interactions on the basis of selected parameters such as the protein primary structure and its characteristic three dimensional shape. 
Within last years the number of published papers as well as the number of journals increase. It is obvious because laboratory methods and available chemicals allow for deep insight into cells and their structures. Majority of papers describe very detailed pathways and theoretical conclusions without paying attention if such pathways really occur [2]. Majority are very detailed but focus on only transcriptomic or proteomic approach while it does not cover overall process up to the final and active product of gene expression including its metabolites. In order to confirm obtained results not only two laboratory methods should be required but also at least two approaches. That is why at least two or more "omics" should be involved in reliable and valuable results [3-8] - results which would allow not only fully to confirm stated hypothesis but also explain particular metabolic pathway from stimulus to biological answer without doubts that part of logic chain of reasoning from transcriptomics via proteomics to functional protein and/or metabolomics was not checked [2] (Fig. 1).

The aim of this review is to pay attention to the selection of appropriate experimental design in order to obtain reliable and valuable results in proteomic, transcriptomic, genomic and even metabolomic studies. The second aim is to integrate proteomic and transcriptomic laboratories in common way to introduce complete "omics" cascade in biological experiments in order to obtain overall picture of examined processes.

\section{Transcriptome}

Transcriptome is an initial product of genome expression. It consists of the set of all RNA molecules that exist in a single cell or tissue, including protein-coding messenger RNA (mRNA) and noncoding RNAs, such as ribosomal RNA (rRNA), transfer RNA (tRNA), micro RNA (miRNA), small interfering RNA (siRNA), long noncoding RNA (lncRNA) and many others $[9,10]$. Transcriptome composition constantly changes and depends on various factors, such as developmental stage and physiological, environmental or pathological conditions $[11,12]$.

Changes in the transcriptome can be examined via different methods such as quantitative reverse transcription PCR (RT-qPCR), serial/cap analysis of gene expression (SAGE/ CAGE), DNA microarrays or RNA sequencing (RNA-seq) technology. Recently, the two latest techniques play pivotal role in the gene expression analysis. Transcriptional regulation has been extensively studied since the advent of microarray and RNA-seq technologies. However, while DNA microarrays allow for the quantification of only a set of predetermined transcripts, RNA-seq enables the analysis of the whole transcriptome, selected mRNA or desired transcripts [13-15]. It has become an established method for transcriptomic profiling of non-model organisms [16, 17].

RNA-seq method has broad application in gene expression research. It is used not only for characterization and quantification of transcripts, but also to study alternative splicing, to identify allele-specific expression or in gene fusion detection. Moreover, comparative analysis performed with RNA-seq is useful in gene regulatory network research $[11,14,18]$.

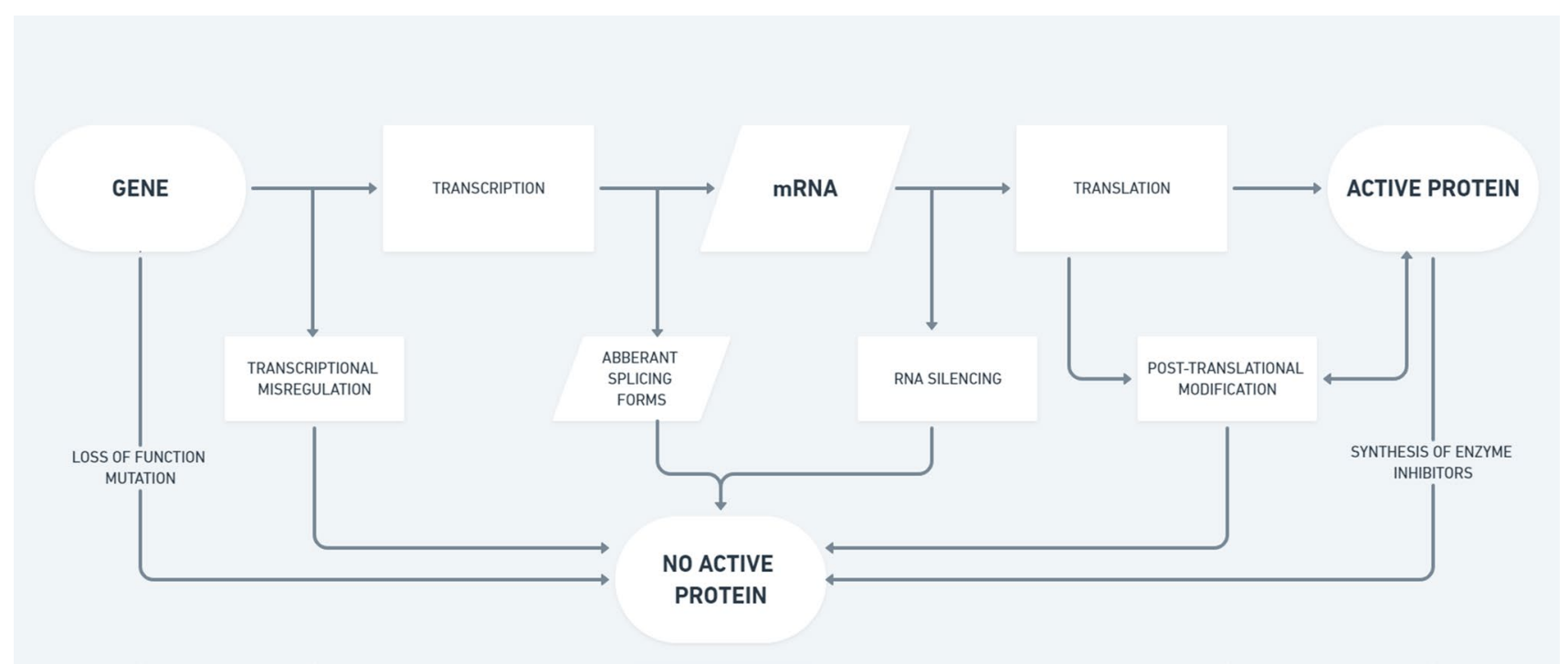

Fig. 1 The relationship gen-protein and the most important factors responsible for finally biologically active or inactive protein 
The details about these techniques are available elsewhere $[13-15,19,20]$. The strategy for their use should be based on expected outcomes related to final product of their action-active protein.

\section{Gene expression regulatory mechanisms}

Due to protein biosynthesis being resources and energyconsuming process, the information flow from genes to proteins is subjected to intricate regulation system $[4,21]$. Each step of gene expression is precisely regulated, starting from transcription control, through mRNA post-transcriptional processing and its decay, translational and post-translational regulation and ending up with protein degradation rate [22].

Until recent technological advances in proteome analysis, it has been common practice to infer protein level from corresponding mRNA abundance. However, the knowledge of transcript level is often insufficient to predict protein abundance. Transcriptomic and proteomic profiling studies showed that the relationship between mRNA and protein levels is complex and strongly influenced by various regulatory mechanism. Protein abundance only partially can be explained by transcript abundance, suggesting the substantial role of the regulatory mechanisms occurring after transcription [3, 4]. Post-transcriptional and post-translational regulation involves alternative splicing, non-coding RNAs (including siRNA, miRNA, lncRNA), RNA-binding proteins (RBPs) as well as protein modification and was in detail described elsewhere [23-29].

As described above, due to the ubiquitous occurrence of post-transcriptional regulation, mRNA is an imperfect indicator of the regulation, modification and activity of proteins in the cell [5]. One of such molecules affecting the regulation of protein production is microRNA. miRNAs are short (20-25 nt) ribonucleic acid molecules that can interfere with mRNA and play a crucial role in post-transcriptional regulation of target gene expression by destabilizing the target mRNA, which consequently leads to inhibition of translation [30] without or with little impact on mRNA level [31]. miRNA molecules resemble 'hairpin' in their shape and have a 2-8 nt length segment in their structure at the 5 ' end called 'seed sequence', which is the primary determinant of target specificity $[23,30]$. This fragment has the ability to interfere with the 'seed match' sequence located in the 3'UTR of the target mRNA [23]. The miRNA effect depends on the degree of this interference. In animals, in most cases, there is imperfect complementarity, which cause the destabilization of target mRNA due to deadenylation and subsequent de-capping, leading to shortened mRNA half-life [32, 33]. In the case of perfect or near-perfect complementarity between the mature miRNA embedded in the RISC (RNAinduced silencing complex) and the target mRNA, mRNA is cleaved and degraded [34]. This is the dominant model of miRNA activity in plants [35], whereas in mammals is rare. An example of such model of action in mammals is miR-196, which causes the cleavage of HOXB8 mRNA [36].

The fact that more than half of the protein-coding genes contain miRNA binding sites [37] and affect on mRNA [30, 38] made them an attractive object for scientists as regulators of gene expression, and thus regulating the levels of proteins in the cell. Despite such a widespread impact of miRNAs on mRNA, studies have shown that their effect on the amount of protein is usually modest [31, 38]. Even in the case of miRNA overexpression, the target protein level is reduced by $<50 \%$, however, even a small change at the protein level may have, in some cases, large physiological consequences [38]. Baek et al. [21] determined that repression at protein level by miR-223 was below $33 \%$ with little or no effect on mRNA levels. Although this is a modest effect, this study showed the ability of miRNA to affect protein levels with little effect on mRNA levels. Furthermore, the contribution of miRNAs to the regulatory feedback loops have been described, through which they may act as buffers of protein levels fluctuation $[38,39]$. On the other hand, it has been reported that the impact of miRNAs on protein production occurs mainly by lowering the level of target mRNAs, through their enhanced degradation [40]. The authors indicate that the decrease in mRNA level caused by miR-1 and miR-223 activity was at least in $84 \%$ responsible for the reduction of protein production efficiency, while only $11-16 \%$ of repression was caused by the reduction of translation efficiency. For another miR-155 it was $93 \%$ and $7 \%$ respectively.

Interestingly, it has been shown that short sequences can occur within the mRNA, which can regulate the translation process of the main coding sequence. Such regulatory fragment is known as uORF [41]. These are the mRNA elements defined by the presence of the start codon (AUG) in the 5 'untranslated region located beyond the main open reading frame, and are estimated to be present in nearly half of the human and murine genes encoding the protein [42]. Due to the fact that eukaryotic ribosomes usually attach the 5 'cap of mRNA and search for the first AUG sequence, uORF may disrupt the efficiency of the protein synthesis process based on the main coding sequence [43]. Calvo et al. [42] observed that the presence of UORF leads to a decrease in mRNA levels of $<30 \%$, whereas it causes a decrease in the level of protein by $30-80 \%$ and indicate that cases in which translation can be completely inhibited are also known.

Moreover, genes (those coding for miRNAs included) are epigenetically regulated. Review of epigenetic mechanisms (such as DNA methylation and histone modification) can be found in in [44-46].

It should be kept in mind that physiological regulation may differ from regulation that appears during pathological processes where additional mechanisms are turned on 
in order to maintain the function of cells. 5'cap dependent translation is the most efficient way of protein synthesis in physiological conditions. In addition cell compartmentation may participate in the regulation of transcription of selected proteins $[47,48]$.

For example, in the case of misfolding stress, the mRNA: protein ratio is disturbed, which is due to the fact that they are regulated with different time patterns, which led to the establishment of a new steady-state of protein level, while the mRNA level returned to the original values [8]. In the case of assessment of only the transcriptome, proteomic changes could not be captured.

The recognition of different mechanisms of control and regulation of translation has clinical importance as it may help to introduce appropriate treatment for example in cancers $[49,50]$.

In order to gain better insight into complex regulatory network of gene expression both transcriptomic and proteomic analyses are required. However, the transcriptome evaluation itself is insufficient to predict the level of protein and obtained results have to be interpreted with great care.

\section{mRNA-protein correlation}

The correlation between mRNA and protein in a cell can be regulated on several levels: at transcription level, mRNA processing level, as well as at translation and protein turnover levels [42], thus the protein level should reflect the dynamic balance between these processes.

It is well known that the mRNA level is lower and less stable than the protein level [6]. However, due to the fact that the transcription somehow initiates the flow of genetic information from DNA to protein, it was thought that the number of transcripts is the main determinant of the protein amount [3].

For this reason, the concentration of mRNA was used as a reflection of the levels and activity of the encoded proteins [3]. However, transcriptome analyses revealed that the regulation of gene expression at the mRNA level exists [51], as there are differences in protein levels over time and between clonally identical cells that may result from, e.g. promoter binding, decay of mRNA, translational rate, and protein degradation index [52]. Thus, the occurrence of post-transcriptional regulation makes mRNA an imperfect indicator of protein activity, regulation and modification [5]. Many of the proteins are present at levels that cannot be predicted from the level of mRNA, which include essential proteins and most transcription factors [5]. Many researchers point to the fact that the main step which determines the protein level in a cell is generally defined as "posttranscriptional regulation" in which processes such as translation rates and its modulation, modulation of protein half-life and delay of protein synthesis are involved [4]. Due to the fact that these processes will affect the process of protein formation, they could be responsible for discrepancies in the relation between protein level and the level of the corresponding mRNA. Moreover, the existing delay between mRNA formation and protein synthesis due to maturation, export and time needed for protein translation will also influence mRNA/protein ratio [53].

Transcript-to-protein levels correlation depends strongly on cells state. In cells that remain at steady state, in stable, unperturbed conditions, changes observed at protein level are predominantly in line with mRNA level variation (e.g. $[54,55])$. However, when subjected to new conditions, cells undergo adaptation which entails various prompt regulatory/ response mechanisms. As protein synthesis requires time, changes in mRNA level are expected to affect protein level with certain delay. This has been shown by Fournier et al. [56] in rapamycin-treated Saccharomyces cerevisiae cells, where mRNA level changes correlated best with protein abundance changes that occurred after 3-5 h.

This delay in protein accumulation in relation to transcript level increase should be taken into consideration during data analysis. Moreover, transcription induction may prove to be too slow to ensure in-time adaptation of cells to new state. Thus, involvement of other mechanisms, such as post-transcriptional regulation of gene expression, may be necessary. Hence, observed variation in protein and transcript abundance may not always correlate [4].

When steady state is perturbed (e.g. during cell differentiation or stress response) or cells are transitioning from perturbed to steady state the dysregulation in correlation between protein and mRNA levels occurs [4]. For example, in budding yeast during the transition from the proliferative to the static phase, the mRNA decreased approximately by $70 \%$, while proteins only by $9.5 \%$ [57]. Moreover, during misfolding stress, there are also dynamic changes in the mRNA and protein levels, which cause perturbation of mRNA: protein ratio. Cheng et al. [8] noted, that significant regulation of the mRNA level occurred in the early phase of the experiment, after which the level returned to the original values. However, in the case of proteins, the concentration changed rapidly during the experiment and a new steadystate level was established, different from the original level.

The evaluation of steady state alterations and regulation could be possible in standardized cell lines and well defined conditions of culture. In case of primary cell lines this approach is very difficult due to wide diversity of factors which may interfere and therefore there are difficulties with standardization of initial conditions of experiment.

Dependencies in the amount of mRNA:protein described above show that usually the imbalance between mRNA and protein levels occurs. Therefore tests based solely on the evaluation of the transcriptome do not necessarily reflect the cell's proteome. Some authors indicate that only about $40 \%$ of the variation in protein concentration can be explained 
by the change in abundance of mRNA $[6,22,58]$, while the remaining part of this variability cannot be explained by measuring only mRNA $[3,22]$. However, on the other hand, some authors indicate that, on a global scale, almost $80 \%$ of variation in protein levels can be explained by a change in mRNA levels. Furthermore, according to Li et al. [59], when experimental errors are taken into account mRNA level is said to explain not $40 \%$ but even up to $84 \%$ of variance in protein level.

Nevertheless, it should be taken into consideration that the relationship between mRNA and protein level varies depending on tissue or cell type, therefore such findings should not be generalized [60].

Koussounadis et al. [61] examined the expression of mRNA and corresponding proteins in ovarian cancer tumour model for 29 genes in different treatment conditions and in untreated control cells. Authors concluded that the correlation between mRNA and proteins depends on differential mRNA expression and the conditions when the determinations were performed.

Moreover, time shift may influence the correspondence between mRNA and protein profile [56, 62]. Another factor is the rate of protein degradation which can be altered but the most significant seems to be the range of posttranslational modifications.

Based on studies conducted on various species, significant role of post-transcriptional regulation during response to stressing conditions was recognized and reviewed in detail in bacteria [63], animals [64] and plants [65]. Due to ethic reasons such experiments can easily by performed in in vitro cell culture but the extrapolation to whole organism should be done with care.

When speaking of discordant and concordant trends in mRNA and protein abundance changes, different methodical approaches need to be taken into account, that is one) global analysis of a whole transcriptomic and proteomic set of data two) gene specific mRNA-protein correlation analysis. When obtained data is compared globally (as in $[6,7]$ ), usually moderate correlation between mRNA and protein level is obtained, making mRNA level insufficient predictor for corresponding protein level. However, gene specific approach may change this situation. As it has been shown by [2], results from transcriptomic analyses may be used as proxies for protein levels when RNA-to-protein (RTP) conversion factor is taken into account. In their study researchers calculated RTP conversion factor by comparing absolute protein copy numbers to corresponding mRNA copy numbers across several human tissues and cell lines. The RTP conversion factor was shown to be gene-specific (it varied from 200 to 220,000 , depending on the gene) and independent of the tissue type. Thus, multiplication of known mRNA copy number by RTP conversion factor allows for individual protein level prediction. This approach greatly improves reliability of using transcriptomic data in protein level prediction (median Pearson's correlation obtained in aforementioned study was higher than 0.9).

\section{Proteome}

The number of papers within the field of proteomics increased significantly due to the access to modern techniques. However, very often the interpretation of data obtained from these modern equipment is not easy and many misinterpretations may appear. Even due to the lack of relationship of these results with transcription, translation or posttranslational modifications which finally may influence protein activity and properties. The presence of mRNA does not mean that respective protein will be synthesized, the presence of new protein does not mean that this molecule is biologically active etc. Moreover, the presence of particular protein does not say anything about the time and way of its synthesis.

Proteomic analysis covers the means to determine the identification and quantitation of proteins as well as protein-protein interactions, protein modifications and localization within cell or tissue. Proteome describes complete protein profile of organism, selected tissue, body fluid or cell. This profile is the result of synthesis based on genomic and transcriptomic data. There are however, additional factors which may influence not only appropriate synthesis itself but also biological activity of these proteins and their breakdown [51]. The question appears when it is enough to describe just protein pattern and when additional transcriptomic data related to examined proteins is necessary in order to confirm the mechanisms lying upon the regulation of relationship between selected genes and selected proteins.

The use of modern equipment resulted in the conclusion that variability of proteins is more complex that could be expected [66]. Up to now the map of protein molecules that are derived from all known genes from one organism is not available. Moreover, it is known that one protein can be divided into few fragments which fall apart but their presence can be confirmed in $2 \mathrm{D}$ electrophoresis. The same protein can be found in few different electrophoretic spots on 2D gels.

Several factors may influence the number of protein molecules which can derive from the same single gene. It includes not only posttranslational modifications but also nucleotide polymorphism, alternative splicing, oxidatively damaged bases and proteolytic cleavage.

There are known examples of different protein molecules derived from the same initial product of protein synthesis having different molecular structures and biological roles. Here VEGF can be the example of several isoforms with different biological activity resulted from the same gene 
vegfa [67]. Covalent modification by phosphorylation or dephosphorylation may activate or inactivate enzymes. Moreover, posttranslational glycosylations are not genetically regulated.

Thanks to recent experiments it can be concluded that the statement one gene-one protein is not obvious any more. There is evidence that one protein can be the product of more than one gene due to the fact that several genes may be involved in final chemical structure and maturation of this protein.

Several studies provided also with clear conclusions that it is possible that one gene can encode more than one protein. This group of proteins is similar with regard to amino acid sequence but differ by chemical structure and biological activity due to alternative splicing at RNA and protein level [68] as well as posttranslational modifications which may lead to topogenesis.

Protein molecules are susceptible to different physical and chemical factors as well as to contacts with other proteins which can modify the interactions between them and influence their biological action.

Biological systems use the regulation of pathways which are yet not fully defined and understood.

The knowledge about the synthesis, activity and function of proteins has not only cognitive character but is especially important for searching for markers of physiological processes as well as mechanisms of different diseases. Pathological conditions may significantly influence all steps in the flow of biological information. The possibility of tracking the source of such marker makes it reliable and valuable for diagnosis. Although protein markers are useful for diagnostic reasons, their analysis will confirm their presence but will not bring the explanation of mechanisms lying upon their source and the way of synthesis. Studies on transcriptomic level are necessary.

\section{Posttranslational modifications}

More than 400 forms of posttranslational modifications are known. The most common are among others phosphorylation, glycosylation, sulfation, nitration, glycation, acetylation, prenylation, methylation, proteolytic cleavage and various forms of oxidation. These modifications may appear at many sites on protein molecule depending on particular amino acids in the chain as chemical structure of these amino acids allows only for selected reactions. Posttranslational modifications are not coded by genes but are crucial for further biological activity of protein including their function, localization within the cell or turnover.

This is the reason why the studies of protein patterns only at abundance level are often of limited value as posttranslational modifications may influence protein activity and function but not reflect its concentration. In this respect mass spectrometry techniques are very useful as they can characterize and quantify posttranslational modifications. This, however, requires appropriate separation and preparation of biological samples in order to detect modifications of interest.

Technological advances and the development of proteomics techniques have enabled the routine quantification of a large number of proteins in the sample [69] and large-scale proteome evaluation, which may contribute to a better understanding of the regulation of gene expression at the level of translation and the influence the proteome has on cells. Moreover, combining these technological methods with statistical tools will enable to analyze the transcriptome and proteome measurements, allowing insight into the dynamics of gene expression process [8].

The analysis of proteome is more complicated as gene sequencing due to high diversity of protein molecules. This is the reason why gel and chromatography based techniques are used for the separation of proteins. Difference in-gel electrophoresis (DIGE) is perfect tool for the comparison between two examined samples which can be analysed in one electrophoretic run what avoids any shift in spots. Mass spectrometry which is used for the identification of obtained spots of interest (ESI (electrospray ionization), MALDI (matrix-assisted laser desorption ionization), stable isotope labeling or label-free quantitation can analyse posttranslational modifications by use of complicated data bases and computer bioinformatic tools [66]. Details about proteomic techniques can be found in specialistic reviews [70, 71].

Since function and behavior of biological systems are mainly governed by the interactions among proteins simple description of protein profile may not be enough to understand the regulation and control of biological processes. The network of all such interactions forms an interactome. The interactome is a very dynamic and cell specific system which describes the interactions within cells and between them. The behavior of cells can be dependent on post translational modifications which are induced by cross-talk between canonical signaling pathway $[72,73]$.

\section{Metabolome}

In result of interactome interactions particular metabolites are synthesized creating metabolome which is specific for particular process or pathways. Metabolome covers all any small molecules (molecular weight up to $2000 \mathrm{Da}$ ) which have water soluble or insoluble character and which are present and can be metabolized in the body. Their functions can be controlled by epigenetic regulation and/or posttranslational modifications. Metabolomic profile can finally confirm if genetic information was transferred properly and obtained protein presents expected activity and function. 
Although very challenging due to high diversity of metabolites any changes in this metabolomic profile can be used for monitoring pathological conditions.

\section{Physiological and pathological conditions}

Transcriptomic and proteomic research can be introduced into the analysis of physiological conditions in order to elucidate particular pathways and their regulation. Pathological conditions interfere with physiological findings both on cell and tissue level. From clinical point of view symptoms of disease are visible but the reasons are deeply hidden and thanks to complex strategy including not only the analysis of markers but also transcriptomic and proteomic level the reasons can be described.

The retention of fetal membranes in cows is the example of peripartum metabolic syndrome where hormonal, genetic and vitaminal/mineral insufficiency may lead to oxidative stress, disturbances in sex steroid profile and protein profile and finally the lack of expulsion of the membranes on time. It is good example to compare and to consider physiological conditions during physiological parturition and pathological situation when fetal membranes instead of being released are retained.

Depending on food regime and availability of supplements as well as the selection of bulls for artificial insemination different metabolic conditions may occur what may influence current status of not only placental but also other cells of organism. Several studies were conducted to evaluate larger or smaller range of metabolites in blood and in placenta but no clear conclusions were drawn with regard to the reasons of the retention [74].

Metabolomic studies [75] compared 20 controls with six animals suffering from retained placenta during the period of 8 weeks before and 8 weeks after parturition. 128 metabolites were identified and quantified in serum out of which 28 and 19 different significantly between 8 and 4 weeks before parturition. Selected amino acids (leucine, lysine, isoleucine, ornithine) and their metabolites such as kynurenine as well as selected lipid compounds showed significantly higher values in animals with retention than healthy cows at eight and 4 weeks before parturition. Lysine, leucine and isoleucine followed similar (significant) trend also between other time points of sample collection.

Transcriptomic studies by means of microarray technique showed 30 differentially expressed genes related to proinflammatory processes as well as processes involved in the release of fetal membranes. Expression of genes for majority of cytokines and chemokines in samples collected immediately after parturition was lower in retained as released placenta, similarly genes responsible for cell adhesion [76]. Lange [77] determined 72 genes which could be linked to processes of placental maturation including those related to the degradation of extracellular matrix and their inhibitors. The conclusions showed that the concentration of mRNA for examined genes was downregulated in placental tissues from cows suffering from the retention of fetal membranes in comparison to samples collected before expected parturition representing immature placenta. In accordance to Streyl et al. [78] genome arrays of samples collected before and at parturition provided with the data that mRNA expression differed significantly with regard to examined genes. Before parturition higher mRNA expression was detected with regard to mitotic cell cycle and tissue differentiation while during parturition prevalent were genes involved in apoptosis, degradation of extracellular matrix as well as innate immune response. Authors did not check the products of mRNA expression.

Proteomic studies on not retained [79] and retained bovine placenta covering electrophoretic map and partial identification were published $[80,81]$. Apart from mentioned above several papers deal with single proteins in healthy cows and those suffering from the retention [82-84]. Moreover, studies on anti adhesive protein Decorin in bovine placenta showed no correlation between mRNA and protein abundance during pregnancy [85].

All these studies express more or less significant changes in examined proteins but the mechanisms of their regulation are not clarified.

Dilly et al. [84] compared mRNA expression for matrix metalloproteinases in released and retained placental tissues with their immunohistochemical localization, western blotting and zymography. The studies on mRNA expression were confirmed by the presence of examined proteins and their biological activity and showed some differences but did not bring final conclusion about the mechanisms of retained placenta.

Yamamoto et al. [86] in their review pointed out several ways of the regulation of these enzymes including transcriptional regulation, proteolytic activation, interaction with tissue inhibitors. Moreover, they can be regulated by allosteric activation in regulatory enzyme centre, modulation of location and activity by interaction with cell surface and molecules of extracellular matrix and endocytic clearance from extracellular environment by low density lipoprotein receptor-related protein one. This review was mentioned here to show clearly how important is integration in research for obtaining results which can fully answer stated question.

Mentioned above studies used not homogenous groupsdifferent in genetic material, parity and food regime as well as different laboratory approach and mainly primary cell lines which made impossible to focus on steady state of cells of interest. In result important data were obtained but still the mechanisms of the retention were not elucidated. With 
this example it should be clear that the answer for question in the title of this presentation is YES.

\section{Conclusions and perspectives}

In conclusion, focusing on one laboratory approach-either proteomic or transcriptomic - may end up with only partial explanation or even misinterpretation of particular process due to the lack of straight dependence between gene and protein. Pathological conditions may even more profoundly interfere with already known physiological pathways.

It is already known that genome analysis answers what can be performed while further transcriptome analysis answers what currently is performing. The addition of proteomic approach helps to elucidate what was done. Finally metabolome profile confirms what was and is going on. Having in mind this cascade of logic events it seems to be obvious that the integration of omics is the best approach for complex interpretation and valid results. Moreover, using in such integrated approach the same biological samples avoids the influence of unexpected factors.

\section{Compliance with ethical standards}

Conflict of interest Authors declare no conflict of interest.

Open Access This article is distributed under the terms of the Creative Commons Attribution 4.0 International License (http://creativeco mmons.org/licenses/by/4.0/), which permits unrestricted use, distribution, and reproduction in any medium, provided you give appropriate credit to the original author(s) and the source, provide a link to the Creative Commons license, and indicate if changes were made.

\section{References}

1. Wang Z, Sun X, Zhao Y, Guo X, Jiang H, Li H, Gu Z (2015) Evolution of Gene Regulation during Transcription and Translation. Genome Biol Evol 7:1155-1167. https://doi.org/10.1093/ gbe/evv059

2. Edfors F, Danielsson F, Hallstrom BM, Kall L, Lundberg E, Ponten F, Forsstrom B, Uhlen M (2016) Gene-specific correlation of RNA and protein levels in human cells and tissues. Mol Syst Biol 12:883-887. https://doi.org/10.15252/msb.20167144

3. Vogel C, Marcotte EM (2012) Insights into the regulation of protein abundance from proteomic and transcriptomic analyses. Nat Rev Genet 13:227-232. https://doi.org/10.1038/nrg3185

4. Liu Y, Beyer A, Aebersold R (2016) On the dependency of cellular protein levels on mRNA abundance. Cell 165:535-550. https ://doi.org/10.1016/j.cell.2016.03.014

5. Ghaemmaghami S, Huh WK, Bower K, Howson RW, Belle A, Dephoure N, O'Shea EK, Weissman JS (2003) Global analysis of protein expression in yeast. Nature 425:737-741. https://doi. org/10.1038/nature02046
6. Schwanhäusser B, Busse D, Li N, Dittmar G, Schuchhardt J, Wolf J, Chen W, Selbach M (2011) Global quantification of mammalian gene expression control. Nature 473:337-342. https://doi. org/10.1038/nature10098

7. Schwanhäusser B, Busse D, Li N, Dittmar G, Schuchhardt J, Wolf J, Chen W, Selbach M (2013) Corrigendum: global quantification of mammalian gene expression control. Nature 495:126-127. https://doi.org/10.1038/nature11848

8. Cheng Z, Teo G, Krueger S, Rock TM, Koh HW, Choi H, Vogel C (2016) Differential dynamics of the mammalian mRNA and protein expression response to misfolding stress. Mol Syst Biol 12:855. https://doi.org/10.15252/msb.20156423

9. Costa V, Angelini C, de Feis I, Ciccodicola A (2010) Uncovering the complexity of transcriptomes with RNA-Seq. J Biomed Biotechnol 2010:19. https://doi.org/10.1155/2010/853916

10. Kashi K, Henderson L, Bonetti A, Carninci P (2016) Discovery and functional analysis of lncRNAs: methodologies to investigate an uncharacterized transcriptome. Biochim Biophys Acta 1859:3-15. https://doi.org/10.1016/j.bbagrm.2015.10.010

11. Marguerat S, Bähler J (2010) RNA-seq: from technology to biology. Cell Mol Life Sci 67:569-579. https://doi.org/10.1007/s0001 8-009-0180-6

12. Han Y, Gao S, Muegge K, Zhang W, Zhou B (2015) Advanced applications of RNA sequencing and challenges. Bioinform Biol Insights 9(suppl 1):29-46. https://doi.org/10.4137/BBI.S28991

13. Kogenaru S, Yan Q, Guo Y, Wang N (2012) RNA-seq and microarray complement each other in transcriptome profiling. BMC Genom 13:629-633

14. Hrdlickova R, Toloue M, Tian B (2017) RNA-Seq methods for transcriptome analysis. Wiley Interdiscip Rev RNA. https://doi. org/10.1002/wrna.1364

15. Knierim E, Lucke B, Schwarz JM, Schuelke M, Seelow D (2011) Systematic comparison of three methods for fragmentation of long-range PCR products for next generation sequencing. PLoS ONE 6:e28240. https://doi.org/10.1371/journal.pone.0028240

16. Ekblom R, Galindo J (2011) Applications of next generation sequencing in molecular ecology of non-model organisms. Heredity 107:1-15. https://doi.org/10.1038/hdy.2010.152

17. Lohse M, Bolger AM, Nagel A, Fernie AR, Lunn JE, Stitt M, Usadel B (2012) RobiNA: a user-friendly, integrated software solution for RNA-Seq-based transcriptomics. Nucleic Acids Res 40(W1):W622-W627. https://doi.org/10.1093/nar/gks540

18. Ozsolak F, Milos PM (2011) RNA sequencing: advances, challenges and opportunities. Nat Rev Genet 12:87-98. https://doi. org/10.1038/nrg2934

19. Wang Z, Gerstein M, Snyder M (2009) RNA-Seq: a revolutionary tool for transcriptomics. Nat Rev Genet 10:57-63. https://doi. org/10.1038/nrg2484

20. Mutz KO, Heilkenbrinker A, Lönne M, Walter JG, Stahl F (2013) Transcriptome analysis using next-generation sequencing. Curr Opin Biotechnol 24:22-30. https://doi.org/10.1016/j. cels.2017.03.003

21. Lahtvee PJ, Sánchez BJ, Smialowska A, Kasvandik S, Elsemman IE, Gatto F, Nielsen J (2017) Absolute quantification of protein and mRNA abundances demonstrate variability in gene-specific translation efficiency in yeast. Cell Syst 4:495-504. https://doi. org/10.1016/j.cels.2017.03.003

22. de Sousa Abreu R, Penalva LO, Marcotte EM, Vogel C (2009) Global signatures of protein and mRNA expression levels. Mol BioSyst 5:1512-1526. https://doi.org/10.1039/b908315d

23. Bartel DP (2009) MicroRNAs: target recognition and regulatory functions. Cell 136:215-233. https://doi.org/10.1016/j. cell.2009.01.002

24. Chen M, Manley JL (2009) Mechanisms of alternative splicing regulation: insights from molecular and genomics approaches. Nat Rev Mol Cell Biol 10:741-754. https://doi.org/10.1038/nrm2777 
25. Prabakaran S, Lippens G, Steen H, Gunawardena J (2012) Posttranslational modification; nature's escape from genetic imprisonment and the basis for dynamic information encoding. Wiley Interdiscip Rev Syst Biol Med 4:565-583. https://doi.org/10.1002/ wsbm. 1185

26. Roy B, Jacobson A (2013) The intimate relationships of mRNA decay and translation. Trends Genet 29:691-699. https://doi. org/10.1016/j.tig.2013.09.002

27. Mitchell SF, Parker R (2014) Principles and properties of eukaryotic mRNPs. Mol Cell 54:547-558. https://doi.org/10.1016/j. molcel.2014.04.033

28. Dykes IM, Emanueli C (2017) Transcriptional and post-transcriptional gene regulation by long non-coding RNA. Genom Proteom Bioinform 15:177-186. https://doi.org/10.1016/j. gpb.2016.12.005

29. Gehring NH, Wahle E, Fischer U (2017) Deciphering the mRNP code: RNA-bound determinants of post-transcriptional gene regulation. Trends Biochem Sci 42:369-382. https://doi.org/10.1016/j. tibs.2017.02.004

30. Bushati M, Cohen SM (2007) MicroRNA functions. Annu Rev Cell Dev Biol 23:175-205. https://doi.org/10.1146/annurev.cellb io.23.090506.123406

31. Baek D, Villen J, Shin C, Camargo FD, Gygi SP, Bartel DP (2008) The impact of microRNAs on protein output. Nature 455:61-71. https://doi.org/10.1038/nature07242

32. Eulalio A, Huntzinger E, Nishihara T, Rehwinkel J, Fauser M, Izaurralde E (2009) Deadenylation is a widespread effect of miRNA regulation. RNA 15:21-32. https://doi.org/10.1261/ rna.1399509

33. Wu L, Fan J, Belasco JG (2006) MicroRNAs direct rapid deadenylation of mRNA. Proc Natl Acad Sci USA 103:4034-4039. https://doi.org/10.1073/pnas.0510928103

34. Hutvagner G, Zamore PD (2002) A microRNA in a multipleturnover RNAi enzyme complex. Science 297:2056-2060. https ://doi.org/10.1126/science.1073827

35. Jones-Rhoades MW, Bartel DP, Bartel B (2006) MicroRNAs and their regulatory roles in plants. Annu Rev Plant Biol 57:19-53. https://doi.org/10.1146/annurev.arplant.57.032905.105218

36. Yekta S, Shih IH, Bartel DP (2004) MicroRNA-directed cleavage of HOXB8 mRNA. Science 304:594-596. https://doi.org/10.1126/ science.1097434

37. Friedman RC, Farh KK, Burge CB, Bartel DP (2009) Most mammalian mRNAs are conserved targets of microRNAs. Genome Res 19:92-105. https://doi.org/10.1101/gr.082701.108

38. Ebert MS, Sharp PA (2012) Roles of MicroRNAs in conferring robustness to biological processes. Cell 149:515-524. https://doi. org/10.1016/j.cell.2012.04.005

39. Siciliano V, Garzili I, Fracassi C, Criscuolo S, Ventre S, di Bernardo D (2013) miRNAs confer phenotypic robustness to gene networks by suppressing biological noise. Nat Commun 4:2364. https://doi.org/10.1038/ncomms3364

40. Guo H, Ingolia NT, Weissman JS, Bartel DP (2010) Mammalian microRNAs predominantly act to decrease target mRNA levels. Nature 466:835-840. https://doi.org/10.1038/nature09267

41. Morris DR, Geballe AP (2000) Upstream open reading frames as regulators of mRNA translation. Mol Cell Biol 20:8635-8642

42. Calvo SE, Pagliarini DJ, Mootha VK (2009) Upstream open reading frames cause widespread reduction of protein expression and are polymorphic among humans. Proc Natl Acad Sci USA 106:7507-7512. https://doi.org/10.1073/pnas.0810916106

43. Kozak M (1991) Structural features in eukaryotic mRNAs that modulate the initiation of translation. J Biol Chem 266:19867-19870

44. Golbabapour S, Abdulla MA, Hajrezaei M (2011) A concise review on epigenetic regulation: insight into molecular mechanisms. Int J Mol Sci 12:8661-8694. https://doi.org/10.3390/ ijms 12128661

45. Gibney ER, Nolan CM (2010) Epigenetics and gene expression. Heredity 105:4-13. https://doi.org/10.1038/hdy.2010.54

46. Morales S, Monzo M, Navarro A (2017) Epigenetic regulation mechanisms of microRNA expression. Biomol Concepts 8:203212. https://doi.org/10.1515/bmc-2017-0024

47. Lin CL, Evans V, Shen S, Xing Y, Richter JD (2010) The nuclear experience of CPEB: implications for RNA processing and translational control. RNA 16:338-348. https://doi. org/10.1261/rna.1779810

48. Udagawa T, Swanger SA, Takeuchi K, Kim JH, Nalavadi V, Shin J, Lorenz LJ, Zukin RS, Bassell GJ, Richter JD (2012) Bidirectional control of mRNA translation and synaptic plasticity by the cytoplasmic polyadenylation complex. Mol Cell 47:253-266. https://doi.org/10.1016/j.molcel.2012.05.016

49. Hanash SM, Bobek MP, Rickman DS, Williams T, Rouillard JM, Kuick R, Puravs E (2002) Integrating cancer genomics and proteomics in the post-genome era. Proteomics 2:69-75

50. Master A, Nauman A (2014) Molekularne mechanizmy inicjacji biosyntezy białek - biochemiczne i biomedyczne implikacje nowego modelu translacji wzmacnianej przez element RNA odpowiedzi na hipoksję (rHRE). (Molecular mechanisms of protein biosynthesis initiation - biochemical and biomedical implications of a new model of translation enhanced by the RNA hypoxia response element (rHRE)). Postępy Biochemii 60:39-54

51. Dermit M, Dodel M, Mardakheh FK (2017) Methods for monitoring and measurement of protein translation in time and space. Mol BioSyst 13:2477-2488. https://doi.org/10.1039/c7mb0 0476a

52. Raser JM, O'Shea EK (2005) Noise in gene expression: origins, consequences and control. Science 309:2010-2013. https://doi. org/10.1126/science.1105891

53. Lee MV, Topper SE, Hubler SL, Hose J, Wenger CD, Coon JJ, Gasch AP (2011) A dynamic model of proteome changes reveals new roles for transcript alteration in yeast. Mol Syst Biol 7:514 519. https://doi.org/10.1038/msb.2011.48

54. Csárdi G, Franks A, Choi DS, Airoldi EM, Drummond DA (2015) Accounting for experimental noise reveals that mRNA levels, amplified by post-transcriptional processes, largely determine steady-state protein levels in yeast. PLoS Genet 11:e1005206. https://doi.org/10.1371/journal.pgen.1005206

55. Lundberg E, Fagerberg L, Klevebring D, Matic I, Geiger T, Cox J, Algenas C, Lundeberg J, Mann M, Uhlen M (2010) Defining the transcriptome and proteome in three functionally different human cell lines. Mol Syst Biol 6:450. https://doi.org/10.1038/ msb.2010.106

56. Fournier ML, Paulson A, Pavelka N, Mosley AL, Gaudenz K, Bradford WD, Glynn E, Li H, Sardiu ME, Fleharty B, Seidel C, Florens L, Washburn MP (2010) Delayed correlation of mRNA and protein expression in rapamycin-treated cells and a role for $\mathrm{Ggc1}$ in cellular sensitivity to rapamycin. Mol Cell Proteom 9:271-284. https://doi.org/10.1074/mcp.M900415-MCP200

57. Marguerat S, Schmidt A, Codlin S, Chen W, Aebersold R, Bähler J (2012) Quantitative analysis of fission yeast transcriptomes and proteomes in proliferating and quiescent cells. Cell 151:671-683. https://doi.org/10.1016/j.cell.2012.09.019

58. Maier T, Guell M, Serrano L (2009) Correlation of mRNA and protein in complex biological samples. FEBS Lett 583:39663973. https://doi.org/10.1016/j.febslet.2009.10.036

59. Li JJ, Bickel PJ, Biggin MD (2014) System wide analyses have underestimated protein abundances and the importance of transcription in mammals. PeerJ 2:e270. https://doi.org/10.7717/peerj .270 
60. Franks A, Airoldi E, Slavov N (2017) Post-transcriptional regulation across human tissues. PLoS Comput Biol 13:e1005535. https ://doi.org/10.1371/journal.pcbi.1005535

61. Koussounadis A, Langdon SP, Um In Hwa, Harrison DJ, Smith VA (2015) Relationship between differentially expressed mRNA and mRNA protein correlations in a xenograft model system. Sci Rep 5:10775-10778. https://doi.org/10.1038/srep10775

62. Vogel C, Silva GM, Marcotte EM (2011) Protein expression regulation under oxidative stress. Mol Cell Proteom 10(M111):009217. https://doi.org/10.1074/mcp.M111.009217

63. Holmqvist E, Wagner EGH (2017) Impact of bacterial sRNAs in stress responses. Biochem Soc Trans 45:1203-1212. https://doi. org/10.1042/BST20160363

64. Biggar KK, Storey KB (2018) Functional impact of microRNA regulation in models of extreme stress adaptation. J Mol Cell Biol 10:93-101. https://doi.org/10.1093/jmcb/mjx053

65. Shriram V, Kumar V, Devarumath RM, Khare TS, Wani SH (2016) MicroRNAs as potential targets for abiotic stress tolerance in plants. Front Plant Sci 7:817-822. https://doi.org/10.3389/ fpls.2016.00817

66. Rotilio D, Della Corte A, D'Imperio M, Coletta W, Marcone S, Silvestri C, Giordano L, Di Michele M, Donati MB (2012) Proteomics: bases for protein complexity understanding. Thromb Res 129:257-262. https://doi.org/10.1016/j.thromres.2011.12.035

67. Vempati P, Popel AS, Mac Gabhann F (2014) Extracellular regulation of VEGF: isoforms, proteolysis, and vascular patterning. Cytokine Growth Factor Rev 25:1-19. https://doi.org/10.1016/j. cytogfr.2013.11.002

68. Warren EH, Vigneron NJ, Gavin MA, Coulie PG, Stroobant V, Dalet A, Tykodi SS, Xuereb SM, Mito JK, Riddell SR, Van den Eynde BJ (2006) An antigen produced by splicing of noncontiguous peptides in the reverse order. Science 313:1444-1447. https:// doi.org/10.1126/science. 1130660

69. Bantscheff M, Schirle M, Sweetman G, Rick J, Kuster B (2007) Quantitative mass spectrometry in proteomics: a critical review. Anal Bioanal Chem 389:1017-1031. https://doi.org/10.1007/ s00216-007-1486-6

70. Delahunty C, Yates JR III (2005) Protein identification using 2D-LC-MS/MS. Methods 35:248-255. https://doi.org/10.1016/j. ymeth.2004.08.016

71. Chiou Shyh-Horng, Chi-Yue Wu (2011) Clinical proteomics: current status, challenges, and future perspectives. Kaohsiung J Med Sci 27:1-14. https://doi.org/10.1016/j.kjms.2010.12.001

72. Fields S, Song OK (1989) A novel genetic system to detect protein protein interactions. Nature 340:245-246. https://doi. org/10.1038/340245a0

73. Barrios-Rodiles M, Brown KR, Ozdamar B, Bose R, Liu Z, Donovan RS, Shinjo F, Liu Y, Dembowy J, Taylor IW, Luga V, Przulj N, Robinson M, Suzuki H, Hayashizaki Y, Jurisica I, Wrana JL (2005) High-throughput mapping of a dynamic signaling network in mammalian cells. Science 307:1621-1625. https://doi. org/10.1126/science. 1105776

74. Bicalho LMS, Lima FS, Ganda EK, Foditsch C, Meira EBS Jr, Machado VS, Teixeria AGV, Oikonomou G, Gilbert RO, Bicalho RC (2014) Effect of trace mineral supplementation on selected minerals, energy metabolites, oxidative stress, and immune parameters and its association with uterine diseases in dairy cattle. J Dairy Sci 97:4281-4295

75. Dervishi E, Zhang G, Mandal R, Wishart DS, Ametaj BN (2018) Targeted metabolomics: new insights into pathobiology of retained placenta in dairy cows and potential risk biomarkers. Animal 12:1050-1059. https://doi.org/10.1017/S17517311170025 06

76. Braunert A (2012) Bedeutung immunologischer Mechanismen für die Pathogenese der Retentio secundinarum beim Rind. Doctoral thesis Faculty of Veterinary Medicine in Munich

77. Lange HSD (2013) Einfluss von Apoptose und Degradation der extrazellulären Matrix auf die Pathogenese der Retentio secundinarum beim Rind. Doctoral thesis Faculty of Veterinary Medicine in Munich

78. Streyl D, Kenngott R, Herbach N, Wanke R, Blum H, Sinowatz F, Wolf E, Zerbe H, Bauersachs S (2012) Gene expression profiling of bovine peripartal placentomes: detection of molecular pathways potentially involved in the release of foetal membranes. Reproduction 143:85-105. https://doi.org/10.1530/REP-11-0204

79. Kim HR, Han RX, Yoon JT, Park CS, Jin DI (2010) A twodimensional electrophoresis reference map for the bovine placenta during late pregnancy. Proteomics 10:564-573. https://doi. org/10.1002/pmic.200900508

80. Kankofer M, Wawrzykowski J, Hoedemaker M (2014) Profile of bovine proteins in retained and normally expelled placenta in dairy cows. Reprod Domes Anim 49:270-274. https://doi. org/10.1111/rda.12266

81. Kankofer M, Wawrzykowski J, Miller I, Hoedemaker M (2015) Usefulness of DIGE for the detection of protein profile in retained and released bovine placental tissues. Placenta 36:246-249. https ://doi.org/10.1016/j.placenta.2014.11.012

82. Walter I, Boos A (2001) Matrix metalloproteinases (MMP-2 and MMP-9) and tissue inhibitor-2 of matrix metalloproteinases (TIMP-2) in the placenta and interplacental uterine wall in normal cows and in cattle with retention of fetal membranes. Placenta 22:473-483. https://doi.org/10.1053/plac.2001.0633

83. Boos A, Stelljes A, Kohtes J (2003) Collagen types I, III and IV in the placentome and interplacentomal maternal and fetal tissues in normal cows and in cattle with retention of fetal membranes. Cells Tissues Organs 174:170-183. https://doi.org/10.1159/000072720

84. Dilly M, Hambruch N, Shenavai S, Schuler G, Froehlich R, Haeger JD, Ozalp GR, Pfarrer C (2011) Expression of matrix metalloproteinase (MMP)-2, MMP-14 and tissue inhibitor of matrix metalloproteinase (TIMP)-2 during bovine placentation and at term with or without placental retention. Theriogenology 75:11041114. https://doi.org/10.1016/j.theriogenology.2010.11.019

85. Guillomot M, Campion E, Prezelin A, Sandra O, Hue I, Le Bourhis D, Richard C, Biase FH, Rabel C, Wallace R, Lewin H, Renard JP, Jammes H (2014) Spatial and temporal changes of Decorin, type I collagen and fibronectin expression in normal and clone bovine placenta. Placenta 35:737-747. https://doi. org/10.1016/j.placenta.2014.06.366

86. Yamamoto K, Murphy G, Troeberg L (2015) Extracellular regulation of Metalloproteinases. Matrix Biol 44-46:255-263. https:// doi.org/10.1016/j.matbio.2015.02.007

Publisher's Note Springer Nature remains neutral with regard to jurisdictional claims in published maps and institutional affiliations. 